\title{
Effects of a Couple Communication Program on Marital Adjustment
}

\author{
Bektas Murat Yalcin and Tevfik Fikret Karahan
}

Background: Couples are usually advised to improve their communication skills to increase harmony and avoid conflicts. However, studies aimed at increasing marital adjustment in primary care are limited.

Methods: A Couple Communication Program was announced at the Ondokuz Mayis University Permanent Education Center, and the Dyadic Adjustment Scale was administered to 67 couples who volunteered. Twenty-eight persons ( 14 couples) with the lowest test scores were randomized into study and control groups. At the end of the program (post-test), the scale was again administered to the study group. Afterward, the pretest and post-test scores of the study and control groups were compared. The study group's pretest, post-test, and follow-up test scores were also examined.

Results: No difference in marital adjustment was found between the study and control groups before the start of the program $(P>.05)$. The post-test scores of the couples attending the Couple Communication Program proved to be higher in total than the scores of those who did not attend $(P<.001)$. The post-test and follow-up scores of the study group were significantly higher than their pretest scores $(P<.001)$. There was no significant difference between the post-test and follow-up scores of the study group $(P=1.0)$.

Conclusion: This program may have a positive effect on marital adjustment levels by improving communication skills and may lead to long-term behavioral modifications in couples. (J Am Board Fam Med 2007;20:36-44.)

Happiness and fulfillment springing from a harmonious marriage can play a crucial role in couples' lives, because these affect their physical and psychological health. ${ }^{1,2}$ Individuals typically make the primary care physician their first port of call for medical and psychosocial problems. ${ }^{3}$ Studies have shown that substantial numbers of divorced and married people turn to their physicians for help with personal problems, suggesting that physicians need to be prepared to help them appropriately. ${ }^{4}$ The biopsychosocial model and the family life circle theory provide frameworks for understanding the common stresses of marital life and also guide

This article was externally peer reviewed.

Submitted April 7, 2006; revised July 31, 2006; accepted August 16, 2006.

From the Department of Family Medicine (BMY), and Faculty of Education, Department of Psychological Counseling and Guidance (TFK), Ondokuz Mayis University, Kurupelit/Samsun, Turkey.

Ethical approval: Permission was obtained from the Ondokuz Mayis University Ethics Committee.

Conflict of interest: none declared.

Corresponding author: Dr. Bektas Murat Yalcin, Ondokuz Mayis University of Medicine Department of Family Medicine University Hospital, 55132 Kurupelit/Samsun, Turkey (E-mail: myalcin@omu.edu.tr). the family physician in recommending strategies to improve marital satisfaction. ${ }^{5}$ Many opportunities have been described that are available to the family physician for detecting distress in troubled marriages and in divorce, as well as for therapeutic intervention, including anticipatory guidance, counseling, family therapy, and, as needed, referral for more intensive therapy. ${ }^{6-8}$

Difficult situations that require referral to a mental health specialist include suicidal or homicidal ideation, intent, or behavior; psychotic behavior; sexual, physical, or substance abuse; somatic fixation; severe marital and sexual problems; and problems resistant to change during primary care counseling. However, many marital or relationship problems can be handled by family physicians if they have adequate training. ${ }^{9}$ Although psychotherapy and counseling for different mental or behavioral problems occupy an important place in many family physicians' practices, other family physicians consider that family therapy is not part of their job. ${ }^{10}$ Busy practices, inadequate undergraduate or postgraduate training, or a failure to identify couples in trouble may cause lack of focus on family therapy. 
One of the best ways to foster a well-adjusted marital relationship is to provide couples with training in communication skills, which will help them resolve future marital conflicts. ${ }^{11,12}$ Studies reveal a high correlation between the communication and conflict resolution skills of couples and marital adjustment and divorce rates. ${ }^{13-21}$ Many patients may prefer to acquire these skills via family therapy in the primary care setting, wishing to avoid the potential stigma attached to referral to outside professionals. A trusting, long-term relationship with their primary care physician may be particularly helpful to such couples. ${ }^{10} \mathrm{~A}$ co-led group with a clinical psychologist may be a solution to a physician's lack of self-confidence and experience, and may avoid time-consuming office visits and financial problems.

This study analyzes the effects of the Couple Communication Program developed by the authors to improve the adjustment levels of married couples. The main questions of the analysis concern whether couples having adjustment problems benefit from a valid, reliable, and practical program, and if so, whether the beneficial effects of the program are maintained over time.

\section{Methods}

\section{Study Framework and Pattern}

The control group pre-post-test model was used as the study pattern. First, posters announced that a Couple Communication Program aimed at improving marital communication would be held at the Ondokuz Mayis University Permanent Education Center between March 1 and May 1, 2005. Sixty-seven couples (134 persons) wishing to solve their marital problems volunteered to participate in the program. The Dyadic Adjustment Scale was administered to each couple.

The study sample consisted of the 28 persons (14 couples) with the lowest test scores. Both the study and control groups consisted of 14 subjects (7 couples), randomly assigned. Before the study each participant received a questionnaire in a sealed envelope requesting demographic information. The study group attended a 10 -week communication skills program, meeting weekly for $1 \frac{1}{2} 2$ hours. Each member of the study group agreed to attend all the sessions. None of the couples ceased attending the program. A final application of the Dyadic Adjustment Scale was administered to both groups at the end of the program. A follow-up test was given 3 months later to all the subjects participating in the Couple Communication Program.

\section{Couple Communication Program}

One of the researchers (TFK) possessed wide experience and knowledge of the field. The other researcher, a family physician (BMY), had a basic knowledge of the field, experience in family counseling, and the skills needed to administer the program (giving constructive feedback, active listening, managing conflict, etc). ${ }^{9,22}$ The authors co-designed the Couple Communication Program, the independent variable in this study. In designing the program the authors took an eclectic approach, referred to many sources, and took cultural factors into consideration. ${ }^{23-42}$ The program has an educative and time-limited structure based on group experience (behavioral modeling). The main aim of the program is to provide couples with basic communication and conflict resolution skills.

The Couple Communication Program consisted of $1 \frac{1 / 2}{2}$-hour sessions on 10 consecutive weekends and was administered jointly by the 2 authors. The sessions were designed as 245 -min segments, separated by a coffee break. Sessions included such techniques as providing skill-related information, role-playing scenarios based on real-life experience, and homework. Sessions 2 through 10 began with a warm-up activity where couples shared their experience with the previous week's homework. Participants were assessed after each session and assigned tasks to perform at home to encourage them to apply what they had learned. The Couple Communication Program agenda is presented in the Appendix.

\section{Data Collection Tool}

Dyadic Adjustment Scale

Spanier ${ }^{43}$ adopted the Dyadic Adjustment Scale (referred to hereafter as "the scale"), designed to assess the adjustment levels of married couples or those living together. The scale, widely used in clinical work and research on marriage and family therapy, consists of 32 questions/themes distributed among 4 sub-inventories, using a Likert scale. The 4 subscales are affectional expression, dyadic cohesion, dyadic consensus, and dyadic satisfaction.

Scale scores range from 0 to 151 , with 0 indicating the lowest level of marital adjustment. In their own reliability study, Sher and Baucom ${ }^{44}$ 


\begin{tabular}{|c|c|c|}
\hline & Study Group & Control Group \\
\hline Mean age (years) & $\begin{array}{c}36 \pm 0.1 \text { year } \\
(\min .32, \text { max. } 44)\end{array}$ & $\begin{array}{c}35 \pm 0.3 \text { years } \\
(\min .31, \text { max. } 45)\end{array}$ \\
\hline Relationship status & Married $=14$ & Married $=14$ \\
\hline Mean duration of marriage (years) & $\begin{array}{c}4.8 \pm 0.2 \\
(\min .0 .2, \max .0 .7)\end{array}$ & $\begin{array}{c}4.1 \pm 0.6 \\
(\min .0 .2, \max .0 .8)\end{array}$ \\
\hline Education status (mean years spent in education) & $\begin{array}{c}11.34 \pm 0.8 \\
(\min .0 .8 . \max .0 .14)\end{array}$ & $\begin{array}{c}11.25 \pm 0.5 \\
(\min .0 .7 . \max .0 .16)\end{array}$ \\
\hline Mean number of children & 1.7 & 1.6 \\
\hline
\end{tabular}

maintained that a score below 101 is a reliable and critical cutoff point for the assessment of marital adjustment. Spanier calculated the Cronbach $\alpha$ coefficient for the whole scale as 0.96 , whereas in replication studies conducted in 1982 these values were 0.91 and 0.96 , respectively. The reliability coefficients obtained for the subscales vary between 0.94 and 0.73 . The expert opinion approach was used for the assessment of content validity, and the scale's simultaneous validity was calculated as a correlation of 0.86 for married couples and 0.88 for divorcees.

Criterion validity analyses have revealed that the scale can differentiate between married and divorced couples, as well as between couples with problems and those without. Demir and Fisiloğlu ${ }^{45}$ conducted validity and reliability assessments of the scale in Turkey. Internal consistency analyses have shown the Cronbach $\alpha$ coefficient of the scale to be 0.95 , whereas its split-half reliability is 0.90 . The subscale $\alpha$ coefficients have been calculated between 0.76 and 0.91. The General Functioning subscale of the Family Assessment Device has been used to determine the scale's structural validity, and the correlation value for the Dyadic Adjustment Scale was determined to be -0.78 , whereas the correlation values for the subscales were between -0.65 and -0.75 .

\section{Statistical Analyses}

The numeric results of the Dyadic Adjustment Scale were dependent variables in this study. The difference between the pretest, post-test, and follow-up test results of the study group was examined using analysis of covariance (one-factor ANCOVA), and Bonferroni's test was used to investigate the relationship between the pair results. The MannWhitney $U$ Test was used to investigate the relation between the pretest and post-test results of the study and control groups. A value of $P<.05$ was regarded as significant. All analyses were performed using SPSS version 13.0 (SSPS, Inc., Chicago, IL).

\section{Results}

The demographic characteristics of both groups are presented in Table 1. The results of the initial Dyadic Adjustment Scale applied to the control and study groups revealed no significant difference in marital adjustment (pretest study group $=82.00 \pm$ 7.76 , pretest control group $=82.42 \pm 8.03, P>$ $.05)$. Post-test scores (at the end of the program) for those attending the Couple Communication Program proved to be higher in total than the scores of those couples who did not attend (post-test study group $=106.07 \pm 12.21$, post-test control group $=$ $82.28 \pm 7.9, \mathrm{U}=6.500, P<.001)$.

The results of the Mann-Whitney $U$ Tests comparing the pretest and post-test scores of both groups are shown in Table 2. There was not a significant difference between the pretest and posttest scores of the control group during the 10-week period $(P=.852)$. The post-test and follow-up test scores of the study group were significantly higher than their pretest scores (study group follow-up scores $=106.21 \pm 12.86, \mathrm{~F}=118.260, P<.001$ ). There was no significant difference between the post-test and follow-up scores of the study group in pair-wise comparison (Bonferroni) $(P=1.0)$.

\section{Discussion}

The Couple Communication Program designed by the authors may have an effect on marital adjustment levels. Not only did the couples attending the program develop better skills compared with the couples in the control group, they also reported an improved feeling of harmony and cooperation. 
Table 2. Mann-Whitney $U$ Test Results Comparing the Total Scores of Both Groups' Dyadic Adjustment Scale

\begin{tabular}{lccccc}
\hline Groups & No. & Row Average & Row Total & U & P \\
\hline Initial Scores & & & & & \\
$\quad$ Pretest study & 14 & 14.18 & 198.50 & 93.500 & 0.836 \\
$\quad$ Pretest control & 14 & 14.82 & 207.50 & .05 \\
Scores at the termination of the program* & & & 294.50 & 6.500 & 0.000 \\
$\quad$ Post-test study & 14 & 21.04 & 111.50 & $P<.001$ \\
$\quad$ Post-test control & 14 & 7.96 & & $P$ \\
\hline
\end{tabular}

*The Dyadic Adjustment Scale was applied to both groups 10 weeks later.

Although the program ran successfully and smoothly, there were some unforeseen problems in which the researchers had to intervene. In general, the male partners had significant problems expressing their emotions during sessions, in particular with giving verbal responses and acceptance messages. Although this had not been planned, the participants were asked to make a list of the emotional and physical features of their spouse that they liked best. Here the male spouses' responses were very basic and superficial, whereas the female spouses' responses were very detailed and emotional. The female spouses held in common the view that they had very deep, basic communication problems with their spouses, even in maintaining a simple conversation. This confirmed our observation that the male spouses often used unhealthy listening modes (superficial, selective, defensive, and trapping) in role play. The male spouses also had difficulty giving feedback to their spouses and using "I" language.

Most of the women had jobs and also carried heavy responsibilities with regard to housework; they felt that they received insufficient help from their spouses. The empathic skills of both sexes were determined to be highly inadequate; they seemed to prefer acting in an egocentric manner, which they particularly disliked when it was displayed by their spouse. The researchers used several empathy-building techniques in a variety of scenarios to improve the couples' skills.

The female spouses claimed that they lost their tempers very often and easily, displaying strong emotions, cursing, taking too long to calm down, sulking, and breaking off communication. Male spouses exhibited more rigid, authoritarian, and judgmental behavior, blaming their wives for problems. The female spouses concluded that during conflicts their husbands acted dominantly and often used threats and commands, which hurt them and made them feel despised. After observing that win/ lose rather than win/win strategies were being used by the couples (and that it was usually the female spouses who lost), role playing was used extensively to give participants practice in structuring win/win situations.

Other couple communication and marriage improvement programs have also resulted in positive effects on marital adjustment levels. ${ }^{23-35}$ Earlier programs contain very similar approaches in their themes, such as active listening skills, ${ }^{25-27,29,46}$ conflict resolution skills, ${ }^{25-27,46,47}$ establishing empathy between spouses, ${ }^{25,26,29,47}$ defining and strengthening the objectives of the marriage, ${ }^{29,46,47}$ and sharing responsibilities..$^{29,46}$

However, our program differs from other improvement programs in that it focuses on improving many unique communication skills. ${ }^{23-35,46,47}$ Some of these unique skills, not used in other programs, are the use of ego-strengthening language, anger management (sharing his/her anger with the spouse through body language and the use of humor and relaxation), and the use of "I" language. In addition, we used a variety of different techniques to modify spouses' behavior and employed a wide range of activities, including role play, discussion, demonstrations, sharing feelings with the group, group experiences, homework, behavioral modeling, behavioral negotiation, etc.

The fact that the study group's adjustment skills remained better than those of the control group even after 3 months may be more significant than their post-test results. Most of the previous studies depended on post-test scores after group therapy to determine behavioral modification. ${ }^{29,32,33,47}$ There are 2 studies in the field that extended the investigation over a longer period of time: L'Abate et $\mathrm{al}^{25}$ administered the follow-up test 3 and 6 months after the program; Butler et $\mathrm{al}^{27}$ administered follow-up tests 3, 6, and 12 months afterward. There 
seems to be consensus that 3 months should be an adequate period. ${ }^{25,27}$ Hence, it may be anticipated that our program will lead to permanent behavioral changes.

This study reveals the opportunities that primary care physicians, in cooperation with clinical psychologists, can provide for patients with family or marital conflict. With adequate training in the behavioral sciences, many family physicians can include marital counseling skills in their clinical repertoires. ${ }^{10,48-50}$ An understanding of the basic techniques of the behavioral sciences can help physicians be more alert to patients' marital problems and better allow them to make appropriate recommendations for more intensive therapy. ${ }^{6,7,10,50}$ With the skills required to support troubled marriages, the family physician of the future may be able to make a significant contribution to the preservation of the nuclear family. ${ }^{51}$

Efforts have been made to integrate the behavioral sciences with medical sciences in residency or postgraduate programs to meet patients' psychosocial needs. ${ }^{52,53}$ However, many studies show that family medicine residency or postgraduate training in psychological therapy needs to be improved. ${ }^{54-56}$ Because family physicians often have to provide psychological therapy or counseling in their daily activities, their training should reflect this need. ${ }^{53-56}$ One of the proposed solutions for couples who have requested marital therapy is short-term group therapy co-led by a resident and a behavioral scientist. ${ }^{57}$ Experience of this kind during residency training can make family physicians more comfortable with marital counseling.

Our study had a number of limitations. Although the participants with the lowest test scores participated in the study, their scores did not imply very severe or complicated marital maladjustments. Therefore our results cannot be generalized to be effective in solving these kinds of problems, including sexual or physical abuse. All the couples in our study were so highly motivated and eager to resolve their family conflicts that none of them stopped attending the program. However, if a spouse is resistant to therapy or fails to attend, this poses a difficult situation for the family physician. ${ }^{9}$ Furthermore, to administer this program family physicians would require basic knowledge and skills in the behavioral sciences and family counseling. It is essential for physicians to have experience in family therapy to help couples overcome difficult situations.

In conclusion, the Couple Communication Program may be a valid, reliable, and practical program for increasing marital adjustment between couples in conflict. The couples attending the program may have acquired new and functional communication skills. This study may help physicians in many ways. First, announcing this type of program via posters may attract couples previously unaware that their physician might help with marital maladjustments, or who may have difficulty sharing their marital problems with the family physician because of personal or cultural factors. This study may also motivate some physicians to run similar programs for their patients. It may be cost effective to run therapy groups for couples who have similar marital problems and who may benefit from the same therapies. And finally, we used very new techniques (ego-shattering language, relaxation, and humor for anger management, etc) to improve communication skills. Physicians may modify programs they run to reflect their own approach. Our results now need to be verified in undergraduate and postgraduate training by long-term studies.

\section{Appendix: The Couple Communication Program Agenda Session 1 \\ Aim}

1) To introduce the participants to each other, to inform them of the attendance policy and their responsibilities; and 2) To discuss the importance of communication and conflict resolution skills in solving marital problems.

\section{Activities}

To discuss the small group study process and the responsibilities of the participants.

To discuss with the group problems within the marital process and how these relate to communication skills.

To discuss communication problems with the group.

\section{Session 2}

Aim

1) To communicate with messages conveying acceptance, tolerance, respect, and value; and 2) To 
achieve the ability to reflect respect and understanding in the couple's communication.

\section{Activities}

\section{Exercises}

To give messages showing their admiration for their spouse's emotional, social, and physical features.

To perceive, decode, and return these messages with positive feedback.

Homework involving these exercises.

\section{Session 3}

Aim

To give spouses the ability to use "ego-strengthening terms" instead of "ego-lowering terms" with each other.

\section{Activities}

To use both ego-lowering and ego-strengthening terms to convey the spouse's emotional, social, and physical characteristics. For example:

- "My spouse has curves" instead of "My spouse is fat."

- "My spouse is delicate and willowy" instead of "My spouse is thin."

- "My spouse is careful with money" instead of "My spouse is a miser."

- "My spouse has firm beliefs" rather than "My spouse is obstinate."

To share feelings resulting from these messages and to compare ego-lowering and ego-strengthening terms with group members.

Homework involving these exercises.

\section{Session 4}

Aim

To gain the ability to use healthy listening methods and to recognize unhealthy modes of listening.

\section{Activities}

A demonstration of ineffective and unhealthy listening modes (superficial, selective, defensive, and trapping).

To practice unhealthy listening modes with the group.

A demonstration of active listening.

To practice effective and active listening modes, such as turning the face and body toward the spouse while listening, making eye contact, nodding, responding verbally, etc.

To compare feelings resulting from healthy and unhealthy listening modes and to share these with the group.

Homework involving healthy listening.

\section{Session 5}

Aim

1) To focus on the difference between "I" language and "You" language; and 2) To gain the ability to use "I" language.

\section{Activities}

A demonstration of "I" language and "You" language.

Practice using "I" and "You" messages, where spouses choose the most irritating examples of "You" messages they have experienced in real life. Examples:

- "Your screaming at me when others were around made me very unhappy" vs. "If you scream at me like that again, I will make you rue the day."

- "I'm really troubled by the fact that you don't clean up the bathroom after you shave" vs. "You are the sloppiest, messiest man I've ever seen."

- "I'm worried about the careless way you spend money" vs. "You are spending money stupidly and inconsistently."

To share the feelings of spouses resulting from their experiences with "I" language and "You" language.

Homework to reinforce the use of "I" language.

\section{Session 6}

Aim

To develop correct and advanced empathy between spouses.

\section{Activities}

To role play some problematic scenarios and to determine spouses' empathy skills.

A demonstration of empathy and advanced proper empathy.

To practice responding with advanced proper empathy.

To share the feelings of couples as they compare how they felt when empathy was and was not present. 


\section{Session 7}

Aim

To provide spouses with anger management skills.

\section{Activities}

To list their spouse's most infuriating behaviors.

To demonstrate how much they react with anger in these situations; for example, by screaming, breaking objects, attacking their spouse, engaging in physical violence, leaving home, refusing to speak to the partner, etc.

To use relaxation and humor techniques.

To express anger toward the spouse using "I" language.

To demonstrate anger management techniques.

To share with the group their feelings about using relaxation and humor techniques.

Homework: To practice relaxation and humor techniques.

\section{Sessions 8 and 9}

Aim

To provide spouses with cooperation-based conflict resolution skills.

\section{Activities}

A demonstration of dysfunctional conflict resolution skills (competition, withdrawal, reconciliation, postponement) and communication barriers.

To share with the group spouses' previous experiences with conflict.

Role play to reveal emotions produced by conflict with spouses.

To note the barriers to communication.

To focus on the body language of the spouse during conflict to understand his/her feelings correctly.

To try to understand the spouse's feelings.

\section{Session 10}

Aim

To share the feelings of the group regarding this program and to evaluate the process of group therapy.

\section{Activities}

To share feelings with the group.

\section{References}

1. Sinha SP, Mukerjee N. Marital adjustment and personal space orientation. J Soc Psychol 1989; 130:633-9.

2. Campbell TL. The effectiveness of family interventions for physical disorders J Marital Fam Ther 2003;29:263-81.

3. Mazonson PD, Mathias SD, Fifer SK, et al. The mental health patient profile: Does it change primary care physicians' practice patterns? J Am Board Fam Pract 1996;9:336-45.

4. Kitson GC, Graham AV, Schmidt DD. Troubled marriages and divorce: A prospective suburban study. J Fam Pract 1983;17:249-58.

5. Swanson JG. Family physicians' approach to psychotherapy and counseling: Perceptions and practices. Can Fam Physician 1994;40:53-8.

6. Starling BP, Martin AC. Improving marital relationships: Strategies for the family physician. J Am Board Fam Pract 1992;5:511-6.

7. Burge SK, Scheineider FD, Ivy L, et al. Patients' advice to physicians about intervening in family conflict. Ann Fam Med 2005;3:348-54.

8. Mayer R, Graham H, Schuberth C, et al. Family system ideas in the 10-minute consultation: Using a reflecting partner or observing team in surgery. Br. J Gen Pract 1996;46:229-30.

9. Campbell TL, Seaburn D, McDaniel SH. Family Stres and Counselling. In: Taylor RB, editor. Family Medicine: Principle and Practice, 6th Ed. New York: Springer-Verlag 1999;272-8.

10. Graham H, Senior R, Lazarus M, et al. Family therapy in general practice: views of referrers and clients. Br J Gen Pract 1992;42:25-8.

11. Fowers BJ, Blaine J. The limits of a technical concept of a good marriage: exploring the role of virtue in communication skills. J Marital Fam Ther 2001;27: $327-40$.

12. Travis RP, Travis PY. Marital health and marriage enrichment. Ala J Med Sci 1975;12:172-6.

13. Christensen A, Shenk JL. Communication, conflict, and psychological distance in non-distressed, clinic, and divorcing couples. J Fam Psychol 1990;4:63-79.

14. Sanders MR, Halford WK, Behrens BC. Parental divorce and premarital couple communication. J Fam Psychol 1998;12:543-556.

15. Lawrence E, Bradbury TN. Physical aggression and marital dysfunction: A longitudinal analysis. J Consult Clin Psychol 2000;68:4-12.

16. Rogge RD, Bradbury TN. Till violence does us part: The differing roles of communication and aggression in predicting adverse marital outcomes. J Fam Psychol 1999;13:60-74.

17. Holtzwort-Munroe A, Smutzler N, Stuart GL. Demand and withdraw communication among couples experiencing husband violence. J Consult Clin Psychol 1998;66:753-60. 
18. Markman HJ, Renick MJ, Floyd FJ, et al. Preventing marital distress through communication and conflict management training: A 4- and 5-year follow-up. J Fam Psychol 1992;6:184-94.

19. Gottman JM, Krokoff LJ. Marital interaction and satisfaction: a longitudinal view. J Consult Clin Psychol 1989;57:47-53.

20. Floyd FJ, Zmich DE. Marriage and the parenting partnership: perceptions and interactions of parents with mentally retarded and typically developing children. Child Dev 1991;62:1434-48.

21. Ponzetti JJ, Cate RM. The developmental course of conflict in the marital dissolution process. J Divorce 1986;10:1-14.

22. Lang F, Marvel K, Sanders D, et al. Interviewing when family members are present. Am Fam Physician 2002;65:1351-1354.

23. Schilling EA, Baucom DH, Burnett CK, et al. Altering the course of marriage: the effect of prep communication skills acquisition on couples' risk of becoming martially distressed. J Fam Psychol 2001;15: $750-68$.

24. Halford WK, Sanders MR, Behrens BC. Can skills training prevent relationship problems in at-risk couples? Four-year effects of a behavioral relationship education program. J Fam Psychol 2001;15: 135-54.

25. Butler MH, Wampler KS. A meta-analytic update of research on the couple communication program. Am J Fam Ther 1999;27:223-37.

26. Cavedo C, Guerney BG. Relationship enhancement enrichment and problem-prevention programs: therapy-derived, powerful, versatile. In: Berger $\mathrm{R}$ and Hannah $\mathrm{M}$, editors. Preventive approaches in couple's therapy. Lillington (NC): Edwards Brothers, 1999. p. 73-8.

27. L'Abate L. Structured enrichment and distance writing for couples. In: Berger R and Hannah M, editors. Preventive approaches in couple's therapy. Lillington (NC): Edwards Brothers, 1999. p. 111-3.

28. Patterson JL, Williams L, Grauf-Graunds C, et al. Essential skills in family therapy: from the first interview to the termination. New York: Guilford Press; 1998.

29. Parrott L III, Parrot L. Relationships. Grand Rapids (MI): Zondervan; 1992.

30. Piercy FP, Sprenkle DH, Wetchler JL. Family therapy sourcebook. 2nd Ed. New York: Guilford Press; 1996.

31. Goldenberg H, Goldenberg I. Family therapy: an overview. 6th Ed. New York: Wadsworth Publishing; 2003.

32. Hahlweg K, Markman HJ, Thurmaier F, et al. Prevention of marital distress: results of a German prospective longitudinal study. J Consul Clin Psychol 1998;66:731-43.

33. Kaiser A, Hahlweg K, Fehm-Wolfsdorf T. The efficacy of a compact psychoeducational group train- ing program for married couples. J Consul Clin Psychol 1998;65:1017-25.

34. Malcom KD. Personal growth in marriage: an Adlerian unilateral marriage enrichment program. Individ Psychol 1992;48:487-92.

35. Brock GW, Joanning HA. Comparison of the relationship enhancement program and the Minnesota couple communication program. J Marital Fam Ther 1983;9:413-21.

36. Schauble PG, Hill CGA. Laboratory approach to treatment in marriage counseling: training in communication skills. Fam Coordinator 1976;277-84.

37. Egan G. You and me. Pacific Grove (CA): Brooks/ Cole; 1997.

38. Egan, G. The skilled helper: A problem-management approach to helping. 6th Ed. Pacific Grove (CA): Brooks/Cole; 1998.

39. Schanake ME. Human relations. Columbus $(\mathrm{OH})$ : Merrill; 1990.

40. Hazaleus SL, Deffenbacher JL. Relaxation and cognitive treatments of anger. J Consul Clin Psychol 1986;2:222-6

41. Quillian S. Body language. Richmond Hill (Ontario): Firefly Books; 2004.

42. Reece BL, Brandt R. Human relations principles and practices. Boston: Houghton Mifflin; 1990.

43. Spanier GB. Dyadic adjustment scale. In: Fredman $\mathrm{N}$, Sherman R, editors. Handbook of measurements for marriage and family therapy. New York: Brunner-Mazel; 1987.

44. Sher TG, Baucom DH. Marital communication: differences among martially distressed, depressed, and non-distressed non-depressed couples. J Fam Psychol 1993;1:148-53.

45. Demir A, Fisiloglu H. Applicability of the dyadic adjustment scale for marital quality with Turkish couples. Eur J Psychol Assess 2000;16:214-18.

46. Freedman CM, Low SM, Markman HJ, et al. Equipping couples with the tools to cope with predictable and unpredictable crisis events: the PREP Program. Int J Emerg Ment Health 2002;4:49-55.

47. Olson DH, Olson AK. Prepare-Enrich Program: version 2000. In: Berger R, Hannah M, editors. Preventive approaches in couples therapy. Lillington (NC): Edwards Brothers; 1999. p. 197-202.

48. Greenberg G, Ganshorn K, Danilkewich A. Solution-focused therapy: counseling model for busy family physicians. Can Fam Physician 2001;47: 2289-95.

49. Jackson L, Tisher M. Family therapy skills for general practitioners. Aust Fam Physician 1996;25: 1261-71.

50. Fosson AR, Elam CL, Broaddus DA. Family therapy in family practice: a solution to psychosocial problems? J Fam Pract 1982;15:461-5.

51. Schmidt DD, Messner E. The role of the family 
physician in the crisis of impending divorce. J Fam Pract 1975;2:99-102.

52. Society of Teachers of Family Medicine Behavioral Science Task Force. Core competency objectives in behavioral science education. Kansas City (MO): Society of Teachers of Family Medicine; 1986.

53. Longlett S, Kruse J. Behavioral science education in family medicine: a survey of behavioral science educators and family physicians. Fam Med 1992;24:2835.

54. Swanson JG. Family physicians' approach to psycho- therapy and counseling: Perceptions and practices. Can Fam Physician 1994;40:53-8.

55. Schwenk TL, Clark CH, Jones GR, et al. Defining a behavioral science curriculum for family physicians: what do patients think? J Fam Pract 1982;15:339_ 45.

56. Thrower SM, Bruce WE, Walton RF. The family circle method for integrating family system concepts in family medicine. J Fam Pract 1982;15:451-547.

57. Contreras R, Scheingold L. Couples groups in family medicine training. J Fam Pract 1984;18:293-6. 